\title{
Differences Between Conduct Disordered and Normal Control Children in Their Tendencies to Escalate or Neutralize Conflicts when Interacting with Normal Peers
}

\author{
Walter Matthys, MD \\ Han De Vries, MS \\ Ankie Hectors, MS \\ Maarten Veerbeek, MS \\ Willeke Heidemann, MS \\ Muriel Goud, MS \\ Jan A.R.A.M. Van Hooff, PhD \\ Herman Van Engeland, MD \\ Utrecht University Hospital, Utrecht, The Netherlands
}

\begin{abstract}
The behavior of conduct disordered (CD) children was compared with normal control (NC) children in interaction with normal peers. Dyads consisting of a) a CD child and a normal peer and b) an NC child and the same normal peer as in a) were observed. CD boys were less able than NC boys to neutralize incipient conflicts. Hitherto most behavioral studies of CD boys have concentrated on their tendency to escalate conflicts but have paid very little attention to their difficulty in neutralizing conflicts.
\end{abstract}

KEY WORDS: Conduct Disorder; Antisocial Behavior; Aggression; Peer Relations; Ethology.

\section{Introduction}

Direct behavioral observation studies of children with persistent antisocial behavior have focused mainly on parent-child interactions, ${ }^{1}$ teacher-child interactions, ${ }^{2}$ and on-task behavior in the classroom. ${ }^{3}$ Little attention has been paid to the interactions of antisocial chil-

Received March 2, 1995; For Revision March 26, 1995; Accepted June 21, 1995.

Correspondence should be addressed to Walter Matthys, Department of Child and Adolescent Psychiatry, Utrecht University Hospital, P.O. Box 85500, 3508 GA Utrecht, The Netherlands. 
dren with their peers. ${ }^{4,5}$ Nevertheless, many symptoms of children belonging to one of the two categories for persistent antisocial behavior in the Diagnostic and Statistical Manual of Mental Disorders ${ }^{6}$ occur not only in interactions with adults but also in interactions with peers. Bullying, initiating physical fights, and deliberately destroying other people's property are symptoms of the category conduct disorder (CD); deliberately annoying others and blaming others for his or her mistakes or misbehavior are symptoms of the category oppositional defiant disorder (ODD).

In an earlier study we were able to demonstrate in a play-session of 25 minutes the behavioral manifestations of CD and ODD children when interacting with peers; ${ }^{7}$ however, it also became apparent in the above mentioned study that the kind of interactive partner (a $\mathrm{CD} /$ ODD child or a normal peer) plays a role in the generation of antisocial behavior of $\mathrm{CD} / \mathrm{ODD}$ children. In addition, the fact that a $\mathrm{CD} /$ ODD child is acquainted with the interactive partner influences the generation of antisocial behavior. In the present investigation, therefore, we studied the behavioral characteristics of CD/ODD children (hereafter referred to as CD children) and normal control (NC) children when interacting with the same unacquainted normal peer.

Children played three games in succession, each lasting for 15 minutes: a competitive game, a cooperative game, and a game in which mutual provocation was involved. These games can be considered as representing critical problematic social situations for school aged children. In their study aimed at constructing a taxonomy of problematic situations for elementary school children Dodge, McClaskey and Feld$\operatorname{man}^{8}$ identified six types of situation; these included Response to Failure, Response to Success, Social Expectations, and Response to Provocations. In the competitive game in our study children had to respond to failure and to success, in the cooperative game social expectations were involved, and in the third game children had to respond to mutual provocations.

To study the behavioral characteristics of $\mathrm{CD}$ children interacting with their normal peers, dyads consisting of a CD child and a normal peer were compared with matched dyads consisting of an NC child with the same normal peer as in the first dyad. Each of the $14 \mathrm{CD}$ children were matched on age and sex with an NC child. We were interested in detecting differences between the CD and the NC children in their social behavior towards the normal peers, who in this design functioned as play partners. To control for sequence, we arranged for seven of the normal peer children to first play with a $C D$ child and then 20 minutes later to play with an NC child; the remain- 
ing seven normal peer children first played with an NC child and afterwards with a CD child. Behaviors were scored using an ethogram. Analyses were performed to detect differences both in the unconditional occurrence of behavior and in the conditional occurrence of behavior.

In our analyses of unconditional occurrence of behavior (i.e., behavior considered independently of the preceding behavior shown by the interactional partner), we expected that $C D$ children would show higher percentages of antisocial behavior (i.e., behavior intended to injure the other child) and lower percentages of prosocial behavior (i.e. behavior intended to benefit the other child) than NC children. Kazdin $^{9}$ draws a distinction between low-frequency, high-intensity antisocial behavior (e.g., fighting, destroying) and high-frequency, low-intensity antisocial behavior (e.g., demanding, denigrating). We expected that over a short period of time the CD children in our study would show high-frequency, low intensity antisocial behavior rather than low-frequency, high intensity antisocial behavior.

Besides analyzing the unconditional occurrence of the behavior types, we also analyzed the conditional occurrence. For this purpose we calculated the proportions of various types of reactive behavior which were performed conditional on the occurrence of some type of behavior shown by the normal peer. We expected that, compared with NC children, CD children would react with more antisocial behavior and with less prosocial behavior in response to behavior of their normal peers. Patterson ${ }^{10}$ has demonstrated that aggressive boys are likely to respond to aversive/antisocial behavior of their mothers, fathers, and siblings by displaying aversive/antisocial behavior. As a result of these counterattacks they escalate conflicts. Likewise, Dodge, Coie, Pettit and Price, ${ }^{11}$ in their study of aggression in groups of boys who were defined according to their sociometric status (popular, rejected, neglected, average), have shown that rejected boys escalate conflicts by responding to aggression with further aggression. To our knowledge, no study has yet investigated whether CD children react to antisocial behavior with less prosocial behavior than do NC children, thus demonstrating how difficult it is for them to neutralize incipient conflicts.

\section{Method}

\section{Subjects}

We used three samples in our study. The CD sample consisted of 14 children who met the criteria for either CD or ODD as set out in the Diagnostic 
and Statistical Manual of Mental Disorders. ${ }^{12}$ These boys $(N=10 ; M$ age $=$ 10 years 3 months, $S D=1$ year 1 month) and girls $(N=4 ; M=11$ years 1 month, $S D=1$ year 8 months) were under inpatient psychiatric treatment at Vosseveld, a division of the Department of Child and Adolescent Psychiatry, Utrecht University Hospital. The NC sample consisted of 10 boys ( $M=10$ years 1 month, $S D=1$ year 5 months) and 4 girls $(M=11$ years 1 month, $S D=5$ months) who attended a regular school. The normal peer (NP) sample consisted of 10 boys ( $M=11$ years, $S D=1$ year 3 months) and 4 girls ( $M=$ 11 years 1 month, $S D=1$ year 3 months) who attended another regular school.

In order to show differences between the groups, we used both the parentcompleted (CBCL) and the teacher-completed (TRF) forms of the Child Behavior Checklist. ${ }^{13}$, ${ }^{14}$ The parent's form ${ }^{13}$ was completed by the subjects' primary care-takers, i.e., the educators in the case of the CD sample and the parents in the case of the NC and NP samples. The Total Behavior Problem score reflects the overall severity of dysfunction. The difference between the Total Behavior Problem Score for the CD group $(M=67.9)$ and the NC group $(M=25.2$ ) was significant, $t(26)=4.15, p<.01$. The CD group also differed significantly from the NP group ( $M=13.3$ ) on the Total Behavior Problem Score, $t(26)=6.21, p<.01$. The Externalizing scale reflects outward-directed problems (e.g., aggression or delinquency). The difference between the Externalizing Score for the CD group $(M=29.1)$ and the NC group $(M=8.8)$ was significant, $t(26)=4.1, p<.01$. The CD group also differed significantly from the NP group $(M=3.9)$ on the Externalizing Score, $t(26)=5.21, p$ $<.01$.

The children's teachers completed the teacher's form (TRF) of the CBCL. ${ }^{14}$ The difference between the Total Behavior Problem Score for the CD group $(M=50.2)$ and the NC group $(M=6.6)$ was significant, $t(26)=6.71, p<$ .01 . The CD group also differed significantly from the NP group $(M=17)$ on the Total Behavior Problem Score, $t(26)=6.0, p<.01$. The difference between the Externalizing Score for the CD group $(M=20.6)$ and the NC group $(M=5.4$ ) was significant, $t(26)=4.43, p<.01$. The CD group also differed significantly from the NP group ( $M=3.3$ ) on the Externalizing Score, $t(26)$ $=4.38, p<.01$.

\section{Procedure}

Subjects were taken from the clinic or regular schools by a research assistant and brought to an observation room which was unfamiliar to either group. Children played three games in succession: a competitive game (Memory), a cooperative game (Zoo), and a provocative game (High Speed Domino); each game lasted for 15 minutes. In the Memory game the child who collected most pairs of cards was the winner. To emphasize the competitive aspect of the game, we asked the children to compare every two minutes the number of cards they had collected; in this way each child was made more aware of being either in the winning or in the losing position. In the Zoo game children were asked to construct a zoo that each of them would like, using a plan and a large number (195) of animal figures. The latter were divided between the two children, one child receiving red animals only and the other green only; 
this was done in order to make the input of each child obvious. Consultation was necessary since there were too many figures for the plan. In the final game, High Speed Domino, each child had to make a figure with upright dominos on a wobbly table. Each child was responsible for the figure on his or her side of the table. However, the two figures connected each other in the centre. Consequently, one child could accidently or deliberately knock over the dominoes, which could be conceived of as a provocation.

Before each game, the rules were explained by the research assistant, whereupon she left the observation room and entered an adjoining room from which she could observe the interactions between the children on a monitor. The sessions were all videotaped. The tapes were timecoded with the Video Timecode Generator. The videotapes were analyzed afterwards by means of the computer behavioral analysis program "Observer". ${ }^{15}$ This was done according to an ethogram (see Appendix) based on the ethogram used in an earlier study. ${ }^{7}$ For analyses, behavioral elements were divided into five categories on the dimension prosocial-antisocial behavior: clearly prosocial (e.g., asking with interest), moderately prosocial (e.g., asking permission), neutral (e.g., neutral communication), moderately antisocial (e.g., urging), clearly antisocial (e.g., denigrating); in addition there was a separate category for solitary behaviors (see Appendix). Inter-observer reliability of the scoring of behavioral elements was computed in nine randomly chosen sessions; mean inter-observer reliability as expressed in Cohen's kappa was $.64 .^{16}$

\section{Data Analysis}

The design of the study is such that dyads consisting of a CD child and an NP child are compared with matched dyads (on age and sex) consisting of an NC child and the same NP child. To test differences between the CD and NC children we used the sign test (one-tailed). ${ }^{17}$

To analyze the unconditional occurrence of behavior, we conducted onetailed sign tests on the normalized frequencies (percentages of the total) of behavioral categories. For example, suppose that for the category 'clearly antisocial behavior' 12 out of the 14 matched pairs of CD-NP and NC-NP dyads showed a difference in the percentage with which the behavior was performed by the $\mathrm{CD}$ and the NC child. Then, the sample size would be reduced from 14 to 12. Suppose that in 10 out of the 12 differences the direction of the difference was in the a priori assumed direction, i.e., the CD child showed proportionally more clearly antisocial behavior towards the NP child than did the NC child towards the same NP child. Then the significance probability of this result would be 0.019 .

For the purpose of analyzing the conditional occurrence of behavior, we considered that all behavioral acts, either by a CD or an NC child, which occurred within 10 seconds after a behavioral act by the NP child were reactive behavior to that act. In the sign test the percentages used are those with which some category of behavior was shown to be conditional upon the occurrence of some behavior type performed by the NP child before. These percentages are calculated relative to the total amount of reactive behavior occuring within 10 seconds of the NP child's behavior. 


\section{Results}

\section{Analyses of Unconditional Occurrence of Behavior}

The analyses of unconditional occurrence of the various categories of behavior frequencies showed no significant differences between CD and NC children in the competitive game nor in the cooperative game. In the provocative game, in 8 out of 9 sessions the CD child showed significantly more clearly antisocial behavior than the NC child ( $p=$ 0.018 ). When in the three games analyses of boys and girls were conducted separately, no significant differences between the CD and the NC group were apparent.

\section{Analyses of Conditional Occurrence of Behavior}

Analyses in the competitive game demonstrated that in 10 out of 12 sessions the CD child reacted to clearly antisocial behavior by the NP child with significantly less neutral behavior than did the NC child ( $p$ $=0.019$ ).

When analyses of boys and girls were conducted separately (Table 1), in 7 out of 8 sessions the CD boy reacted to moderately antisocial behavior by the NP boy with significantly less neutral behavior than did the NC boy $(p=0.032)$. Also, in 6 out of 6 sessions the CD boy reacted to clearly antisocial behavior by the NP boy with significantly less moderately prosocial behavior than did the NC boy $(p=0.016)$.

In the cooperative game, in 9 out of 11 sessions the $\mathrm{CD}$ child reacted to moderately antisocial behavior by the NP child with significantly more moderately antisocial behavior than did the NC child $(p=$ 0.033). In addition, in 8 out of 9 sessions the CD child reacted to moderately prosocial behavior by the NP child with significantly more clearly antisocial behavior than did the NC child ( $p=0.018$ ).

When analyses of boys and girls were conducted separately (Table 1), in 7 out of 7 sessions the CD boy reacted to moderately prosocial behavior by the NP boy with significantly more clearly antisocial behavior than did the NC boy $(p=0.008)$. In addition, in 8 out of 9 sessions the CD boy reacted to moderately antisocial behavior by the NP boy with significantly more moderately antisocial behavior than did the NC boy $(p=0.018)$. In 6 out of 6 sessions the CD boy reacted to clearly antisocial behavior by the NP boy with significantly less clearly prosocial behavior than did the NC boy $(p=0.016)$. Finally, in 5 out of 5 sessions the CD boy reacted to moderately antisocial behav- 
Table 1

Conditional Occurence of Behavior: Average Percentages with Which the Conduct Disordered (CD) and Normal Control (NC) Boys Reacted with Some Type of Behavior to Various Types of Behavior Shown by the Normal Peer

\begin{tabular}{|c|c|c|c|c|}
\hline $\begin{array}{l}\text { Behavior of } \\
\text { Normal Peer }\end{array}$ & $\begin{array}{l}\text { Reactive Behavior of } \\
C D \text { or NC boy }\end{array}$ & \multicolumn{2}{|c|}{$\begin{array}{c}\text { Average } \\
\text { Percent- } \\
\text { ages of } \\
\text { Reactive } \\
\text { Behavior }\end{array}$} & $p$-value \\
\hline \multicolumn{5}{|l|}{ Competitive game } \\
\hline moderately antisocial & neutral & 11 & 19 & 0.032 \\
\hline clearly antisocial & moderately prosocial & 1 & 16 & 0.016 \\
\hline \multicolumn{5}{|l|}{ Cooperative game } \\
\hline moderately prosocial & clearly antisocial & 13 & 2 & 0.008 \\
\hline moderately antisocial & moderately antisocial & 21 & 13 & 0.018 \\
\hline clearly antisocial & clearly prosocial & 3 & 14 & 0.016 \\
\hline moderately antisocial & solitary & 1 & 3 & 0.032 \\
\hline \multicolumn{5}{|l|}{ Provocative game } \\
\hline solitary & clearly antisocial & 9 & 1 & 0.032 \\
\hline clearly antisocial & neutral & 7 & 24 & 0.016 \\
\hline
\end{tabular}

*one-tailed sign test

ior by the NP boy with significantly less solitary behavior than did the NC boy $(p=0.032)$.

In the provocative game, in 5 out of 5 sessions the CD child reacted to solitary behavior by the NP child with significantly more clearly antisocial behavior than did the NC child ( $p=0.032$ ).

When analyses of boys and girls were conducted separately (Table 1 ), in 5 out of 5 sessions the CD boy reacted to solitary behavior by the NP boy with significantly more clearly antisocial behavior than did the NC boy $(p=.032)$. In addition, in 6 out of 6 sessions the CD boy reacted to clearly antisocial behavior of the NP boy with significantly less neutral behavior than did the NC boy $(p=0.016)$.

\section{Discussion}

Although CD children hardly differed from NC children in the percentages of antisocial and prosocial behavior shown (unconditional occurrence of behavior), they did differ when these types of behavior were considered in response to different types of behavior performed 
by the normal peer (conditional occurrence of behavior) and when, in comparisons, only the boys' behaviors were involved.

With respect to the role of gender, the behavioral manifestation of CD probably is more difficult to assess in girls than in boys. It has been demonstrated that girls make more use of indirect means of aggression (e.g., manipulation), whereas boys employ more direct means (e.g., hitting) ${ }^{18}$ Indirect aggression (and covert antisocial behavior) is, by definition, more difficult to observe than direct aggression (and overt antisocial behavior). Moreover, many indirect means of aggression (e.g., spreading untrue rumors about a person, making friends with somebody else to obtain revenge $)^{18}$ cannot occur in dyadic interactions with an unacquainted peer such as we arranged in the present study.

The absence of clear differences between $\mathrm{CD}$ and $\mathrm{NC}$ boys in the unconditional occurrence of behavior was unexpected. It is possible that the relatively structured sessions of the present study elicit less antisocial and aggressive behavior than do free play sessions. There is evidence that aggression is more likely to occur during ambiguous play contexts of a rough nature than during unambiguous contexts such as cooperative play and parallel play. ${ }^{11}$ However, in spite of the absence of differences in the percentages of the behavior types (unconditional occurrence) between $\mathrm{CD}$ and NC boys, clear differences could be demonstrated in reactive behavior (conditional occurrence).

In the competitive game, $\mathrm{CD}$ boys reacted to moderately antisocial behavior by the normal peer with less neutral behavior than did NC boys. In addition, CD boys reacted to clearly antisocial behavior by the normal peer with less moderately prosocial behavior than did NC boys. CD boys thus were less able to neutralize incipient conflicts. This was also observed in the two other games: in the cooperative game, CD boys reacted to clearly antisocial behavior by the normal peer less frequently with clearly prosocial behavior than did NC boys; in the provocative game, $\mathrm{CD}$ boys reacted to clearly antisocial behavior by the normal peer with less neutral behavior than did NC boys. Thus, in all three games CD boys reacted to antisocial behavior by the normal peer with less prosocial and neutral behavior than did NC boys. In other words, throughout the play session CD boys showed that they had difficulties in neutralizing incipient conflicts.

Until now, in research hardly any attention has been paid to CD boys' difficulties in neutralizing conflicts. By contrast, much attention has been given to the high tendency of CD boys to escalate conflicts. 
For example, both Patterson ${ }^{10}$ and Dodge et al. ${ }^{11}$ have shown that aggressive boys in their families, and rejected boys in the peer group escalate conflicts by responding to aggression with further aggression. The results of the current study show that besides investigating how far CD boys show more inadequate behavior than do NC boys in response to antisocial behavior by others, we also need to investigate to what extent $\mathrm{CD}$ boys show less adequate behavior in response to this antisocial behavior. In other words, we need to give attention not only to the differences between CD and NC boys in their tendencies to escalate conflicts, but also to the differences in their tendencies to neutralize conflicts. Possibly, this neglect in the literature is due to the rather inconspicuous nature of the types of behavior used to neutralize incipient conflicts. In this context it is worth mentioning that in research on non-human primates refined ethological methods ${ }^{19}$ are used to investigate how different species of primates cope with conflicts through conciliatory behavior. For more than a decade now this topic has been a central issue in ethological studies on aggression. ${ }^{20}$

In the present study, escalation of conflicts in CD boys was demonstrated only in one game: in the cooperative game CD boys reacted to moderately antisocial behavior by the normal peer with more moderately antisocial behavior than did NC boys. It may be that the relatively structured nature of the sessions decreased the likelihood of counterattacks.

Finally, in reaction to behavior that was in no way antisocial, CD boys showed more antisocial behavior than NC boys. Indeed, in the cooperative game, CD boys reacted to moderately prosocial behavior by the normal peer with more clearly antisocial behavior than did NC boys. And in the provocative game, CD boys reacted to solitary behavior by the normal peer with more clearly antisocial behavior than did NC boys. Thus, by reacting to the normal peers' prosocial and solitary behaviors with antisocial behaviors CD boys initiated conflicts.

Some limitations of the study need to be considered. First of all, sample sizes were rather small. This may have been the reason why some a priori expectations were not fulfilled in this study. Secondly, CD children were under inpatient psychiatric treatment in which much attention was paid to the training of adequate social skills. It might be that differences between untreated CD children and NC children are in fact more pronounced than the differences found in the current study. 
One merit of the present study is its design which is new for behavioral studies of CD children.

In conclusion, the main finding of the study is that in interactions with a normal peer CD boys have more difficulties in neutralizing incipient conflicts than do NC boys. This characteristic of CD boys seems to be relevant for their treatment. Indeed, in cognitive-behavioral therapy ${ }^{21}$ (e.g., Anger Coping Training) ${ }^{22}$ children learn to use social problem-solving skills in order to respond adequately to aggressive, aversive, and anger provoking stimuli. Specifically, children not only learn that in order to prevent escalation of the conflict they should not react to these stimuli with antisocial behavior, but they also learn how they should react in order to neutralize the conflict, i.e., with prosocial and neutral behaviors (e.g., making a joke, remaining friendly, ignoring).

\section{Summary}

In this direct behavioral observation study a clear design was used: dyads consisting of a CD child in interaction with a normal peer were compared with dyads of an NC child in interaction with the same normal peer as in the first dyad. Children played three games: a competitive game, a cooperative game, and a provocative game. Play sessions lasted for 45 minutes. Behaviors were scored using an ethogram. CD children hardly differed from NC children in the percentages of antisocial and prosocial behavior shown (unconditional occurrence of behaviors), but they differed in several instances when these types of behavior were considered in response to behavior of the normal peer (conditional occurrence of behavior) and when, in comparisons, only the boys were involved. Throughout the play session, CD boys had more difficulties than NC boys in neutralizing incipient conflicts in that they reacted to antisocial behavior by the normal peer with less prosocial and less neutral behavior than did NC boys. Behavioral studies of CD boys paid particular attention to the tendency of $C D$ boys to escalate conflicts but have neglected their difficulties in neutralizing conflicts. This is unfortunate since this characteristic is relevant for treatment: CD boys not only must learn what they should not do in response to antisocial behaviors of their peers (react with counterattacks), but must also learn what they should do (show prosocial and neutral behaviors). 


\section{References}

1. Reid J: A social learning approach to family intervention: Vol 2. Observation in home settings. Eugene, OR: Castalia, 1978.

2. Breiner J, Forehand R: An assessment of the effects of parent training on clinicreferred children's school behavior. Behavioral Assessment 3: 31-42, 1981.

3. Atkins M, Pelham W, Licht M: The development and validation of objective classroom measures for the assessment of conduct and attention deficit disorders. In Advances in behavioral assessment of children and families, Vol. 4. ed. Prinz $\mathbf{R}$. Greenwich, CT: JAI Press, 1988.

4. McMahon RJ, Forehand R: Conduct Disorders. In Behavioral Assessment of Childhood Disorders, ed. Mash E, Terdal LG. New York: Guilford Press, 1988.

5. Reid J, Baldwin D, Patterson G, Dishion T: Observations in the Assessment of Childhood Disorders. In Assessment and Diagnosis in Child Psychopathology, ed. Rutter M, Tuma A H, Lann I. New York: Guilford Press, 1988.

6. American Psychiatric Association: Diagnostic and Statistical Manual of Mental Disorders, 4th edition (DSM-IV). Washington, DC: American Psychiatric Association, 1994.

7. Matthys W, Van Loo P, Pachen V, De Vries H, Van Hooff J, Van Engeland H: Behavior of conduct disordered children in interaction with each other and with normal peers. Child Psych Hum Dev 25, 1995.

8. Dodge K, McClaskey C, Feldman E: Situational approach to the assessment of social competence in children. $J$ Consult Clin Psychol 53: 344-353, 1985.

9. Kazdin A: Conduct Disorders in Childhood and Adolescence. Newbury Park, CA: Sage, 1987.

10. Patterson G: Coercive Family Process. Eugene, OR Castalia, 1982.

11. Dodge K, Coie J, Pettit G, Price J: Peer status and aggression in boys' groups: developmental and contextual analyses. Child Development 61: 1289-1309, 1990.

12. American Psychiatric Association: Diagnostic and Statistical Manual of Mental Disorders, 3rd edition-revised (DSM-III-R). Washington, DC: American Psychiatric Association, 1987.

13. Achenbach T: Manual for the Child Behavior Checklist and 1991 Profile. Burlington, VT: University of Vermont, Department of Psychiatry, 1991.

14. Achenbach T: Manual for the Teacher's Report Form and 1991 Profile. Burlington, VT: University of Vermont, Department of Psychiatry, 1991.

15. Noldus L: The observer-computer software for behavioural research, version 3.0; instruction manual. Wageningen, the Netherlands: Noldus Information Technology, 1992.

16. Hollenbeck A: Problems of reliability in observational research. In Observing Behavior. Vol. 2 ed. Sackett G. Baltimore: University Park Press, 1978.

17. Siegel S, Castellan N: Nonparametric statistics for the behavioral sciences, 2nd edition. New York: McGraw-Hill, 1988.

18. Lagerspetz $\mathrm{K}$, Björkqvist $\mathrm{K}$, Peltonen $\mathrm{T}$ : Is indirect aggression typical of females? Gender differences in aggressiveness in 11- to 12-year-old children. Aggressive Behavior 14: 403-414, 1988.

19. Kappeler P, Van Schaik C: Methodological and evolutionary aspects of reconciliation among primates. Ethology, 92: 51-69, 1992.

20. Waal F de: Peacemaking among primates. Cambridge, MA: Harvard University Press, 1989.

21. Webster-Stratton C: Annotation: Strategies for helping families with conduct-disordered children. I Child Psychol Psychiat, 32: 1047-1062, 1991.

22. Lochman J, Lampron L, Gemner T, Harris, S: Anger coping intervention with aggressive children: a guide to implementation in school settings. In Innovations in clinical practice: a source book, Vol. 6 ed. Keller P, Heyman S. Sarasota, Fl: Professional Resource Exchange, 1987. 


\section{Appendix: ETHOGRAM}

\section{CLEARLY PROSOCIAL BEHAVIOR}

Treat kindly: comfort, compliment, apologize to or thank the other person

Act in an interested way: ask personal questions

Tease in a friendly way

Laugh: vocalized

Express enthusiasm: while playing a game

\section{MODERATELY PROSOCIAL BEHAVIOR}

Ask permission: take the opinion of another person into account

Comply: with a person's wish, request or command

Constructive criticism: offer a better alternative

Take the initiative: spontaneously express a wish or make a proposition

Smile: aimed at a person

\section{NEUTRAL BEHAVIOR}

Neutral communication: communication without prosocial or antisocial intention

Refer to the rules of a game

Express oneself

Talk about oneself: talk about personal issues in a neutral way

\section{MODERATELY ANTISOCIAL BEHAVIOR}

Urge: vocally and persistently claim attention

Brag, bluff

Show off: by noise and/or mimicking

Express discontent: with reference to the game and/or the situation (not to the person)

Physical abuse of objects

\section{CLEARLY ANTISOCIAL BEHAVIOR}

Resistance: act contrary to a person's wish or request without offering an alternative

Demand: insist that a person obeys your wishes

Vocal abuse

Physical abuse of persons: hit, kick, pull, bite

Laugh scornfully 
Denigrate: express oneself in a provocative, arrogant or mean way about a person and his or her actions

Deliberately making the dominoes fall over (only in the provocative game)

SOLITARY BEHAVIOR

Physical behavior: express insecurity in a non-verbal way, e.g., scratch oneself

Look around 